\title{
Knowledge, awareness, attitude and medication compliance in patients with hypertension
}

\author{
Tengiz Verulava ${ }^{\circledR}$, Giorgi Mikiashvili \\ Caucasus University, Tbilisi, Georgia
}

\begin{abstract}
Background: Recognition of the importance of systolic blood pressure (SBP) level has been considered as one of the major public health challenges in the prevention and treatment of hypertension HTN. Studies indicate that most of the patients with HTN don't control the SBP. The purpose of the study was to assess the patients' knowledge, awareness and attitude towards HTN, especially related to SPB and their compliance with antihypertensive treatment. Material and methods: The quantitative, descriptive, cross-sectional study has been conducted and Morisky Medication Adherence Scale was used.

Results: Most of patients have sufficient general knowledge about HTN. However, they know less about the specific factors associated with their disease, in particular: $77 \%$ of patients were unaware about their systolic blood pressure (SBP) at the time of HTN diagnosis and 75\% — at the last visit to the doctor. The main reasons for the patient low compliance with treatment were low availability of medicines due to high costs $(n=44 ; 22 \%)$, daily chores that prevent from taking medication continuously at the proper time $(\mathrm{n}=32 ; 16 \%)$, forgetfulness of taking medications $(\mathrm{n}=24,12 \%)$.

Conclusions: Recognition of the importance of SBP level has been considered as one of the major challenges of public health and medicine in the prevention and treatment of HTN. The study emphasizes the necessity to maximize the effectiveness of HTN prevention and control programs to achieve optimal control of SBP.
\end{abstract}

Key words: hypertension; systolic blood pressure; patient awareness

Arterial Hypertens. 2021, vol. 25, no. 3, pages: 119-126

DOI: $10.5603 / A H . a 2021.0021$

\section{Introduction}

Improving public knowledge and awareness of hypertension (HTN), its early identification, proper treatment and control significantly reduces the mortality rate caused by cardiovascular diseases [1-4]. In many countries, national high systolic blood pressure (SPB) education programs have been introduced to improve public knowledge and awareness of HTN
[5], through which significant positive results were achieved [6, 7].

Recognition of the importance of SBP level has been considered as one of the major public health challenges in the prevention and treatment of HTN [8]. Despite of improving general knowledge and awareness, some studies indicate that most of the patients with HTN don't control the SBP [9-11] and have poor drug compliance [12]. 
The purpose of the study was to assess the patients' knowledge, awareness and attitude towards HTN, especially related to SPB and there compliance with antihypertensive treatment.

\section{Material and methods}

Quantitative, descriptive, cross-sectional research has been conducted at outpatient departments in Chapidze Emergency Cardiology Center and in Caucasus Medical Centre, which are one of the largest cardiology medical institutions in Georgia.

A non-probabilistic random sampling technique was used. A total of 247 participants were approached; 112 in Chapidze Emergency Cardiology Center, 135 in cardiology department in Caucasus Medical Centre. Of the total participants who were approached and who consented, 200 patients with HTN were found eligible; 92 (46\%) from Chapidze Emergency Cardiology Center, 108 (54\%) from cardiology department in Caucasus Medical Centre. Overall response rate was $81 \%$.

HTN was determined at $\geq 140 / 90 \mathrm{~mm} \mathrm{Hg}$ using the standardized measurement method at least twice. There were included patients with a SBP higher than $140 \mathrm{~mm} \mathrm{Hg}$ and a diastolic blood pressure (DBP) of more than $90 \mathrm{~mm} \mathrm{Hg}$. Patients with pregnancy, under the age of 18 and with mental disorder were excluded from the study.

The research tool consisted of a pre-structured questionnaire, developed by using the existing literature to assess the knowledge and awareness of hypertensive patients [13]. Some changes were made while compiling the questionnaire, taking into account the local culture and environment. Patients who met the inclusion criteria were interviewed to assess their knowledge and awareness of HTN.

The Morisky Medication Adherence Scale was used to study behavior related to patients' compliance with treatment [14]. The Morisky Medication Adherence Scale consists of 8-point questions (never/rarely/sometimes/often/always) and open-ended questions about the reasons for not following the treatment plan. The score range of scale contained low $(<6)$, medium $(6$ to $<8$ ) and high patient compliance with treatment $(=8)$. The study was conducted during October-December 2020.

The ethical clearance was obtained from Ethical Committee of Caucasus University. The questionnaire was accompanied by instruction and description that the survey was anonymous, patients and doctors did not indicate the personal data for not being identified (name, surname, personal number and other data).
The data collected during the study were analyzed using $23^{\text {th }}$ version of the IBM SPSS program.

\section{Results}

The data on major demographic and HTN risk factors are shown in Table 1.

Patients' awareness and knowledge about HTN are shown in Tables 2 and 3. The results show that

Table 1. Demographic data and risk factors in patients with hypertension (HTN)

\begin{tabular}{|c|c|}
\hline \multicolumn{2}{|l|}{ Variables } \\
\hline Sex & \\
\hline Man & $105(52 \%)$ \\
\hline Female & $95(48 \%)$ \\
\hline Age [years] & \\
\hline $30-39$ & $27(13.6 \%)$ \\
\hline $40-49$ & $45(22.6 \%)$ \\
\hline $50-59$ & $63(31.7 \%)$ \\
\hline $60-70$ & $44(22.1 \%)$ \\
\hline$>70$ & $20(10.1 \%)$ \\
\hline Education & \\
\hline Incomplete secondary education & $39(19.8 \%)$ \\
\hline Secondary education & $68(34.5 \%)$ \\
\hline Higher education & $90(45.7 \%)$ \\
\hline Body mass index $\left[\mathrm{kg} / \mathrm{m}^{2}\right]$ (body weight/body height) & \\
\hline Normal & $64(32 \%)$ \\
\hline Overweight & $80(40 \%)$ \\
\hline Obesity & $56(28 \%)$ \\
\hline Alcohol consumption [mL/day] & \\
\hline Does not consume (0 or sometimes) & $64(32.2 \%)$ \\
\hline Moderate consumption (1-100) & $79(39.7 \%)$ \\
\hline High consumption (> 100) & $56(28.1 \%)$ \\
\hline Physical exercises & \\
\hline Low & $87(43.7 \%)$ \\
\hline Moderate & $79(37.7 \%)$ \\
\hline High & $33(16.6 \%)$ \\
\hline Tobacco consumption & \\
\hline Non-smoker (0) & $85(43.1 \%)$ \\
\hline Smoker $(>1)$ & $112(56.9 \%)$ \\
\hline Blood cholesterol [mmol/L] & \\
\hline Normal (5.2) & $57(28.6 \%)$ \\
\hline Borderline (5.2-6.5) & $93(46.7 \%)$ \\
\hline $\operatorname{High}(>6.5)$ & $49(24.6 \%)$ \\
\hline SBP level indicator [mm Hg] & \\
\hline $120 / 80$ & $39(19.6 \%)$ \\
\hline $130 / 85$ & $71(35.7 \%)$ \\
\hline $140 / 90$ & $56(28.1 \%)$ \\
\hline $160 / 95$ & $29(14.6 \%)$ \\
\hline Duration of HTN & \\
\hline $1-5$ years & $55(27.8 \%)$ \\
\hline $5-10$ years & $90(42.4 \%)$ \\
\hline$>10$ years & $55(27.8 \%)$ \\
\hline
\end{tabular}


Table 2. Patients' awareness of hypertension (HTN)

\begin{tabular}{|c|c|c|c|c|}
\hline Patient awareness of HTN & Yes & $\%$ & no & $\%$ \\
\hline Normal SBP level is $120 / 80 \mathrm{~mm} \mathrm{Hg}$ & 142 & 71 & 58 & 29 \\
\hline SBP increase $>140 / 90$ means HTN & 140 & 70 & 60 & 30 \\
\hline $\mathrm{SBP}$ is the pressure during the heart's contraction & 142 & 71 & 58 & 29 \\
\hline DBS is the pressure in the period between heartbeats & 104 & 52 & 96 & 48 \\
\hline SBP increases with aging & 132 & 66 & 68 & 34 \\
\hline Both women and men have equal chances of developing HTN & 102 & 51 & 98 & 49 \\
\hline Genetic traits of HTN increases HTN development risk & 146 & 73 & 54 & 27 \\
\hline Tobacco consumption increases HTN development risk & 130 & 65 & 70 & 35 \\
\hline Alcohol consumption increases HTN development risk & 144 & 72 & 56 & 28 \\
\hline Intake of large amounts of table salt increases HTN development risk & 144 & 72 & 56 & 28 \\
\hline Intake of fatty food increases HTN development risk & 126 & 63 & 74 & 37 \\
\hline Obesity increases HTN development risk & 152 & 76 & 48 & 24 \\
\hline Stress increases HTN development risk & 120 & 60 & 80 & 40 \\
\hline Frequent fast-food consumption (for example, McDonald's, KFC) increases SBP & 134 & 67 & 66 & 33 \\
\hline Sedentary lifestyle increases HTN development risk & 128 & 64 & 72 & 36 \\
\hline HTN can lead to a life-threatening condition & 126 & 63 & 74 & 37 \\
\hline Adherence to antihypertensive treatment & 148 & 74 & 52 & 26 \\
\hline Regular physical exercises help to normalize SBP & 136 & 68 & 64 & 32 \\
\hline Healthy diet helps to normalize SBP & 124 & 62 & 76 & 38 \\
\hline Not paying attention at high SBP can lead to development of stroke, heart attack or heart failure & 138 & 69 & 62 & 31 \\
\hline
\end{tabular}

Table 3. Patients' knowledge about hypertension (HTN)

\begin{tabular}{|l|c|c|c|c|}
\hline Patients' knowledge about HTN & Yes & $\%$ & No. & $\%$ \\
\hline I know I have HTN & 170 & 85 & 30 & 15 \\
\hline When I was diagnosed with HTN, I had already knew about my SBP level & 46 & 23 & 154 & 77 \\
\hline I know my SBP level & 110 & 55 & 90 & 45 \\
\hline SBP control reduces disease complications & 130 & 65 & 70 & 35 \\
\hline Uncontrolled HTN can lead to organ damage & 92 & 46 & 108 & 54 \\
\hline During my last visit to the doctor, I knew my SBP level & 50 & 25 & 150 & 75 \\
\hline I think, HTN is a curable disease & 180 & 90 & 20 & 10 \\
\hline I think, lifestyle changes reduce HTN development & 132 & 66 & 68 & 34 \\
\hline My SBP has been improved over the past year & 146 & 73 & 54 & 27 \\
\hline
\end{tabular}

$66 \%$ of patients had sufficient knowledge about HTN; however, $77 \%$ of them were unaware of their SBP at the time of HTN diagnosis, 45\% were unaware of their SBP level and 74\% felt that to take medication is essential for blood pressure control.

Patients were interviewed for their compliance with treatment of HTN (Tab. 4). The results showed that $43 \%$ of patients sometimes forgot to take the medication and $26 \%$ sometimes purposely did not take prescribed medication. Patients were asked to specify the reasons for their non-compliance with HTN treatment (Tab. 5). The main reasons were: shortage of medicines $(\mathrm{n}=44 ; 22 \%)$, daily chores that prevented them from taking medication continuously at the proper time $(\mathrm{n}=32 ; 16 \%)$, forgetfulness of taking medicines $(\mathrm{n}=24,12 \%)$.

The study has showed a correlation between the patient age and awareness of HTN $(p=0.016<0.05)$. Family members and friends were named as the main sources of getting information. (Tab. 6)

The study has showed a correlation between the alcohol consumption, tobacco consumption and ge- 
Table 4. Compliance with treatment in hypertensive patients

\begin{tabular}{|c|c|c|c|c|}
\hline Patient compliance with hypertensive medication & Yes & $\%$ & No. & $\%$ \\
\hline Do you sometimes forget to take medication? & 86 & 43 & 114 & 57 \\
\hline $\begin{array}{l}\text { Sometimes people deliberately do not take prescribed medications. Is this also a case for you? } \\
\text { In the past two weeks, have you deliberately missed any medication? }\end{array}$ & 52 & 26 & 148 & 74 \\
\hline Have you ever stopped or changed taking prescribed medication without consulting a doctor? & 24 & 12 & 176 & 88 \\
\hline $\begin{array}{l}\text { When going somewhere and leaving the house (e.g., travel), have you ever forgotten to take your } \\
\text { medication? }\end{array}$ & 50 & 25 & 150 & 75 \\
\hline Did you take the medication yesterday? & 156 & 78 & 44 & 22 \\
\hline $\begin{array}{l}\text { When you feel that your health is under control and you feel much better, have you stopped taking the } \\
\text { medication? }\end{array}$ & 26 & 13 & 174 & 87 \\
\hline $\begin{array}{l}\text { Some people do not believe that it's necessary to take medication every day. Have you ever felt being } \\
\text { frustrated because of following a treatment plan? }\end{array}$ & 28 & 14 & 172 & 86 \\
\hline
\end{tabular}

Table 5. The main reasons for the low patient compliance with hypertension (HTN) treatment plan

\begin{tabular}{|l|c|c|}
\hline From your point of view, what is the reason that sometimes you do not follow HTN treatment plan? & N & $\%$ \\
\hline Insufficient knowledge about the disease and long-term treatment neglect & 14 & 7 \\
\hline Adverse reactions to medications & 18 & 9 \\
\hline I do not believe, that health improvement is depended on medical treatment & 16 & 8 \\
\hline I have a fear of taking medication & 12 & 6 \\
\hline Forgetfulness, sometimes I forget taking medication & 24 & 12 \\
\hline Medication shortages, sometimes medications are out of stock at pharmacies & 44 & 22 \\
\hline Lacking communication with the doctor, lack of awareness about the treatment & 14 & 7 \\
\hline Prescribing medication is associated with costs (doctor's fee, transportation costs to the doctor) & 26 & 13 \\
\hline Some medications are too expensive and I cannot afford to buy them & 28 \\
\hline Daily chores, that prevent from taking medication continuously at the proper time & 14 \\
\hline Lack of reminder & 32 & 16 \\
\hline I'm busy with work and sometimes I do not take the medication & 20 & 10 \\
\hline I'm away from home on weekends or I'm on vacation and sometimes I cannot take the medication & 20 & 10 \\
\hline I have to take too many medications and sometimes I skip some of them & 18 & 9 \\
\hline
\end{tabular}

Table 6. Relation between patient's age and awareness of hypertension (HTN)

\begin{tabular}{|c|c|c|c|c|c|c|c|}
\hline \multirow[b]{2}{*}{ Age } & & \multicolumn{5}{|c|}{ Information sources about HTN } & \multirow[b]{2}{*}{ Total } \\
\hline & & Family members & $\begin{array}{l}\text { Acquaintances, } \\
\text { friends }\end{array}$ & Mass media & Medical books & Doctor & \\
\hline \multirow{2}{*}{$30-39$} & Count & 13 & 6 & 3 & 1 & 5 & 28 \\
\hline & $\%$ & $46.4 \%$ & $21.4 \%$ & $10.7 \%$ & $3.6 \%$ & $17.9 \%$ & $100.0 \%$ \\
\hline \multirow{2}{*}{$40-49$} & Count & 6 & 18 & 13 & 3 & 5 & 45 \\
\hline & $\%$ & $13.3 \%$ & $40.0 \%$ & $28.9 \%$ & $6.7 \%$ & $11.1 \%$ & $100.0 \%$ \\
\hline \multirow{2}{*}{$50-59$} & Count & 8 & 22 & 18 & 7 & 8 & 63 \\
\hline & $\%$ & $12.7 \%$ & $34.9 \%$ & $28.6 \%$ & $11.1 \%$ & $12.7 \%$ & $100.0 \%$ \\
\hline \multirow{2}{*}{$60-70$} & Count & 15 & 9 & 13 & 6 & 1 & 44 \\
\hline & $\%$ & $34.1 \%$ & $20.5 \%$ & $29.5 \%$ & $13.6 \%$ & $2.3 \%$ & $100.0 \%$ \\
\hline \multirow{2}{*}{$>70$} & Count & 7 & 6 & 4 & 0 & 3 & 20 \\
\hline & $\%$ & $35.0 \%$ & $30.0 \%$ & $20.0 \%$ & $0.0 \%$ & $15.0 \%$ & $100.0 \%$ \\
\hline \multirow{2}{*}{ Total } & Count & 49 & 61 & 51 & 17 & 22 & 200 \\
\hline & $\%$ & $24.5 \%$ & $30.5 \%$ & $25.5 \%$ & $8.5 \%$ & $11.0 \%$ & $100.0 \%$ \\
\hline
\end{tabular}


Table 7. Correlation between hypertension (HTN) development risks and education level

\begin{tabular}{|c|c|c|c|c|}
\hline & Incomplete secondary & Secondary & Higher & Overall \\
\hline \multicolumn{5}{|c|}{ Alcohol consumption increases HTN development risk } \\
\hline Yes & $19(48.7 \%)$ & $22(31.9 \%)$ & $57(62 \%)$ & $98(49 \%)$ \\
\hline No & $11(28.2 \%)$ & 38 (55.1\%) & $21(22.8 \%)$ & $70(35 \%)$ \\
\hline Don't know & $9(23.1 \%)$ & $9(13 \%)$ & $14(15.2 \%)$ & $32(16 \%)$ \\
\hline Total & $39(100 \%)$ & $69(100 \%)$ & $92(100 \%)$ & $200(100 \%)$ \\
\hline \multicolumn{5}{|c|}{ Tobacco consumption increases HTN development risk } \\
\hline Yes & $18(46.2 \%)$ & $35(50.7 \%)$ & $47(51.1 \%)$ & $100(50 \%)$ \\
\hline No & $10(25.6 \%)$ & $24(34.8 \%)$ & $25(27.2 \%)$ & $59(29.5 \%)$ \\
\hline Don't know & $11(28.2 \%)$ & $10(14.5 \%)$ & $20(21.7 \%)$ & $41(20.5 \%)$ \\
\hline Total & $39(100 \%)$ & $69(100 \%)$ & $92(100 \%)$ & $200(100 \%)$ \\
\hline \multicolumn{5}{|c|}{ Genetic traits of HTN increases HTN development risk } \\
\hline Yes & $20(51.3 \%)$ & $20(29 \%)$ & $50(54.3 \%)$ & $90(45 \%)$ \\
\hline No & $8(20.5 \%)$ & $32(46.4 \%)$ & $14(15.2 \%)$ & $54(27 \%)$ \\
\hline Don't know & $11(28.2 \%)$ & 17 (24.6\% & $28(30.4 \%)$ & $56(28 \%)$ \\
\hline Total & $39(100 \%)$ & $69(100 \%)$ & $92(100 \%)$ & $200(100 \%)$ \\
\hline
\end{tabular}

Table 8. Correlation between the level of blood cholesterol and the body mass index (BMI)

\begin{tabular}{|c|c|c|c|c|}
\hline & $\begin{array}{c}\text { Blood cholesterol } \\
{[\mathrm{mmol} / \mathrm{L}] \text { Normal } 5.2}\end{array}$ & $\begin{array}{c}\text { Borderline } \\
(5.2-6.5)\end{array}$ & $\begin{array}{l}\text { High } \\
6.5+\end{array}$ & Total \\
\hline \multicolumn{5}{|c|}{ BMI $\left[\mathrm{kg} / \mathrm{m}^{2}\right]$ (body weight/squared body height) } \\
\hline $18-24$ & $31(53.4 \%)$ & $22(23.7 \%)$ & $11(22.4 \%)$ & $64(32.0 \%)$ \\
\hline $25-30$ & $18(31.0 \%)$ & $44(47.3 \%)$ & $18(36.7 \%)$ & $80(40.0 \%)$ \\
\hline $30+$ & $9(15.5 \%)$ & $27(29.0 \%)$ & $20(40.8 \%)$ & $56(28.0 \%)$ \\
\hline Total & $58(100 \%)$ & $93(100 \%)$ & $49(100 \%)$ & $200(100 \%)$ \\
\hline \multicolumn{5}{|c|}{ Intake of fatty food increases HTN development risk } \\
\hline Yes & $36(62.1 \%)$ & $37(39.8 \%)$ & $20(40.8 \%)$ & $93(46.5 \%)$ \\
\hline No & $14(24.1 \%)$ & $41(44.1 \%)$ & $20(40.8 \%)$ & $75(37.5 \%)$ \\
\hline I do not know & $8(13.8 \%)$ & $15(16.1 \%)$ & $9(18.4 \%)$ & $32(16.0 \%)$ \\
\hline Total & $58(100.0 \%)$ & $93(100.0 \%)$ & 49 (100.0\%) & $200(100.0 \%)$ \\
\hline
\end{tabular}

netic predisposition to HTN development and education level. Most patients with higher education are aware of HTN development risk as a result of both alcohol $(\mathrm{n}=57 ; 62 \%)$ and tobacco consumption $(\mathrm{n}=47 ; 51.1 \%)$ and genetic predisposition $(\mathrm{n}=50$; 54.3\%). Thus, education level plays an important role in the treatment of HTN and patient behavior $(\mathrm{p}=0.025<0.05)($ Tab. 7$)$.

The study has showed a correlation between the blood cholesterol level and the body mass index $(\mathrm{p}=0.0001<0.05)$. The higher body mass index means the higher blood cholesterol level (40.8\%, $\mathrm{n}=20$, high cholesterol $>6.5 \mathrm{mmol} / \mathrm{L}$ ). The lower body mass index, the lower blood cholesterol (53.4\%; $\mathrm{n}=31$, normal cholesterol $5.2 \mathrm{mmol} / \mathrm{L}$ ).

The study has also showed that $62.1 \%$ of respondents $(\mathrm{n}=36)$ knew that the intake of fatty food is directly related to an increase in blood cholesterol; therefore, this small group had a normal blood cholesterol level of $5.2 \mathrm{mmol} / \mathrm{L}$. However, according to the results of the study, most of them were unaware of that dependence, respectively, $44.1 \%(n=41)$ had borderline blood cholesterol $(5.2-6.5 \mathrm{mmol} / \mathrm{L})$ and $40.8 \%(\mathrm{n}=20)$ had high level (higher than $6.5 \mathrm{mmol} / \mathrm{L})$ (Tab. 8).

The study has showed a correlation between patients' SBP levels and their physical exercise intensity level $(\mathrm{p}=0.02<0.05)$. The results clearly show that the SBP level and physical activity are inversely proportional to each other, with physical activity being low among all groups.

The study also showed a correlation between patients' SBP levels and the frequency of intake of large amounts of table salt $(\mathrm{p}=0.003<0.05)$. Patients with high SBP $(160 / 85 \mathrm{~mm} \mathrm{Hg})$ had insufficient knowledge about the harmful effects of consuming large amounts of table salt $(44.8 \% ; \mathrm{n}=13)$. Patients with relatively low SBP $(120 / 80 \mathrm{~mm} \mathrm{Hg})$ $(61.0 \% ; n=25)$ were aware of the harmful effects of table salt (Tab. 9). 
Table 9. Correlation between patients' systolic blood pressure (SBP) levels and their physical activity and intake of large amounts of table salt

\begin{tabular}{|l|c|c|c|c|c|}
\hline \multicolumn{2}{|l|}{$\begin{array}{c}\text { Your SBP level: } \\
\text { systolic/diastolic } \\
\mathbf{1 2 0 / 8 0}\end{array}$} & $\mathbf{1 3 0 - 8 5}$ & $\mathbf{1 4 0 - 9 0}$ & $\mathbf{1 6 0 - 8 5}$ & All \\
\hline \multicolumn{7}{|l|}{ Physical exercise intensity } & $19(46.3 \%)$ & $25(34.2 \%)$ & $27(47.4 \%)$ & $17(58.6 \%)$ & $88(44.0 \%)$ \\
\hline Low & $17(41.5 \%)$ & $35(47.9 \%)$ & $19(33.3 \%)$ & $8(27.6 \%)$ & $79(100 \%)$ \\
Medium & $5(12.2 \%)$ & $13(17.8 \%)$ & $11(19.3 \%)$ & $4(13.8 \%)$ & $33(16.5 \%)$ \\
High & $41(100.0 \%)$ & $73(100.0 \%)$ & $57(100.0 \%)$ & $29(100.0 \%)$ & $200(100.0 \%)$ \\
Total & $25(61.0 \%)$ & $30(41.1 \%)$ & $26(45.6 \%)$ & $6(20.7 \%)$ & $87(43.5 \%)$ \\
\hline Intake of large amounts of table salt increases HTN development risk & $30(41.1 \%)$ & $26(45.6 \%)$ & $13(44.8 \%)$ & $76(38.0 \%)$ \\
\hline Yes & $7(17.1 \%)$ & $13(17.8 \%)$ & $5(8.8 \%)$ & $10(34.5 \%)$ & $37(18.5 \%)$ \\
No & $9(22.0 \%)$ & $73(100.0 \%)$ & $57(100.0 \%)$ & $29(100.0 \%)$ & $200(100.0 \%)$ \\
\hline I do not know & $41(100.0 \%)$ &
\end{tabular}

\section{Discussion}

Most of patients had sufficient general knowledge about HTN. They knew the importance of SBP in the development of a life-threatening condition (63\%), that its control reduces the complications of the disease $(65 \%)$ or the development of diseases such as stroke, heart attack or heart failure (69\%). These results are consistent with the results of other studies $[15,16]$.

Regardless of general knowledge about HTN, patients were less aware of specific factors related to their disease status, in particular: $45 \%$ were unaware of their SBP levels, although the average duration of the HTN disease was amounted to 5-10 years; $29 \%$ were unaware of the normal SBP level or indicated, that the normal SBP is $140 \mathrm{mmHg}$ or more. These results are consistent with the results of other studies $[17,18]$.

The studies confirm that knowledge of HTN is related to the control of SBP $[19,20]$. SBP is one of the major risk factors for cardiovascular disease. In this regard, it is important to assess the extent to which patients are aware of the importance of controlling their SBP levels.

A significant proportion of the patients were unaware of their SBP at the time of HTN diagnosis $(77 \% ; \mathrm{n}=154)$, and were unaware of their SBP at the last visit to the doctor $(75 \% ; \mathrm{n}=150)$, so they mistakenly thought that their SBP was satisfactory. This confirms that patients were unaware of the importance of hypertension in the process of controlling SBP and were unable to classify accurately SBP levels. These results of the study show that patients' perceptions of their SBP levels do not reflect their actual levels.

Studies confirm the importance of awareness and knowledge about HTN and the potential impact of
SBP education programs. Patients who knew that an increase in SBP levels results in a reduction in life expectancy were more likely to adhere to a treatment regimen than the patients with low awareness [21, $22]$. SBP control and patient compliance with treatment are achieved through education. In this regard, there is a need for medical staff to improve patients' education and awareness of the importance of high SBP levels.

The study showed that family members $(24.5 \%$; $\mathrm{n}=22)$, acquaintances $(30.5 \% ; \mathrm{n}=61)$ and mass media $(25.5 \% ; \mathrm{n}=51)$ were the main information sources for improvement of patients knowledge and awareness of HTN.

HTN can be controlled with lifestyle changes as well as taking medications. Pharmacological treatment of HTN reduces SBP, which has a positive effect on the cardiovascular system. Lifestyle changes to lower SBP include moderate tobacco and alcohol consumption, restriction of salt intake, regular physical exercises, healthy diet habits and weight loss. Lifestyle changes play a crucial role in reducing the number of medications both in hypertensive patients and also in preventing the HTN development in the whole population $[23,24]$.

Studies confirm that patients' low compliance with treatment is a fairly common and significant challenge that is a barrier to effective management of HTN and leads to ineffective treatment [25-27]. A significant proportion of patients sometimes forget to take medication $(43 \% ; \mathrm{n}=86)$, and sometimes they do not take the prescribed medication on purpose $(26 \% ; n=52)$. The main reasons for the low patient compliance with treatment were low availability of medicines due to high costs $(\mathrm{n}=44 ; 22 \%)$, daily chores, that prevented them from taking medication continuously at the proper time $(\mathrm{n}=32 ; 16 \%)$, forgetfulness of taking medications $(\mathrm{n}=24,12 \%)$. The 
study emphasizes the necessity to maximize the effectiveness of HTN prevention and control programs to achieve optimal control of SBP.

Adherence to antihypertensive treatment remains an important element in controlling hypertension [28]. Interventions to improve treatment adherence can be classified as informational, behavioral, or social [29]. Informational interventions use educational, cognitive tactics to increase patient understanding of their condition and its treatment. Behavioral interventions use influence techniques to change patient behaviors by modelling, reminding, or rewarding preferred behaviors. Social interventions recruit family members to assist the patient in improving medication adherence. Approaches may differ in intensity (individual, group), implementation methods (face-to-face, using technology), and essential specialists (physician, health personnel) [30].

\section{Conclusion, recommendations}

The patients has sufficient knowledge about HTN, however they were less aware of their own disease status. Most patients have low compliance with treatment, which is due to the low availability, high cost of medicines, daily chores and forgetfulness of taking the medicines. The study emphasizes the necessity to maximize the effectiveness of HTN prevention and control programs.

\section{References}

1. Gaziano JM. Global Burden of Cardiovascular Disease. In: Braunnwald E, Zipes DP, Libby P. ed. Heart Disease: A Textbook of cardiovascular medicine. 6th ed. WB Saunders Company, Philadelphia 2001: 1-17.

2. Verulava T, Jorbenadze R, Lordkipanidze A, et al. Readmission after hospitalization for heart failure in elderly patients in Chapidze Emergency Cardiology Center, Georgia. J Health Res. 2021; ahead-of-print, doi: 10.1108/jhr-07-2020-0294.

3. Law MR, Frost CD, Wald NJ. By how much does dietary salt reduction lower blood pressure? III - Analysis of data from trials of salt reduction. BMJ. 1991;302(6780): 819-824, doi: 10.1136/ bmj.302.6780.819, indexed in Pubmed: 1827353.

4. Verulava T, Jorbenadze R, Gonghadze A. Pre-operative anxiety in patients with congenital heart diseases. J Cardiovasc Dis Res. 2021; 12(1): 105-109.

5. Roccella E, Horan M. The National High Blood Pressure Education Program: Measuring progress and assessing its impact. Health Psychol. 1988; 7(Suppl): 297-303, doi: 10.1037/0278-6133.7.suppl.297, indexed in Pubmed: 3243223.

6. Hunink MG. The Recent Decline in Mortality From Coronary Heart Disease, 1980-1990. The Effect of Secular Trends in Risk Factors and Treatment. JAMA. 1997; 277(7): 535, doi: 10.1001/ jama.1997.03540310033031, indexed in Pubmed: 9032159.

7. Burt VL, Whelton P, Roccella EJ, et al. Prevalence of hypertension in the US adult population. Results from the Third National Health and Nutrition Examination Survey, 1988-1991. Hyper- tension. 1995; 25(3): 305-313, doi: 10.1161/01.hyp.25.3.305, indexed in Pubmed: 7875754.

8. Rocella E, Burt V, Horan M, et al. Changes in hypertension awareness, treatment, and control rates 20-Year trend data. Ann Epidemiol. 1993; 3(5): 547-549, doi: 10.1016/10472797(93)90114-j, indexed in Pubmed: 8167835.

9. Alexander M, Tekawa I, Hunkeler E, et al. Evaluating hypertension control in a managed care setting. Arch Intern Med. 1999; 159(22): 2673-2677, doi: 10.1001/archinte.159.22.2673, indexed in Pubmed: 10597757.

10. Berlowitz DR, Ash AS, Hickey EC, et al. Inadequate management of blood pressure in a hypertensive population. N Engl J Med. 1998; 339(27): 1957-1963, doi: 10.1056/ NEJM199812313392701, indexed in Pubmed: 9869666.

11. Sadeghi C, Khan HA, Gudleski G, et al. Multifaceted strategies to improve blood pressure control in a primary care clinic: A quality improvement project. Int J Cardiol Hypertens. 2020; 7: 100060, doi: 10.1016/j.ijchy.2020.100060, indexed in Pubmed: 33447781.

12. Pirasath S, Sugathapala AGH, Wanigasuriya K. Descriptive Cross-Sectional Study on Knowledge, Awareness, and Adherence to Medication among Hypertensive Patients at a Tertiary Care Centre in Colombo District, Sri Lanka. Int J Hypertens. 2020; 2020: 1320109, doi: 10.1155/2020/1320109, indexed in Pubmed: 32832144.

13. Oliveria SA, Chen RS, McCarthy BD, et al. Hypertension knowledge, awareness, and attitudes in a hypertensive population. J Gen Intern Med. 2005; 20(3): 219-225, doi: 10.1111/j.15251497.2005.30353.x, indexed in Pubmed: 15836524.

14. Uchmanowicz B, Jankowska EA, Uchmanowicz I, et al. SelfReported Medication Adherence Measured With Morisky Medication Adherence Scales and Its Determinants in Hypertensive Patients Aged $\geq 60$ Years: A Systematic Review and Meta-Analysis. Front Pharmacol. 2019; 10: 168, doi: 10.3389/ fphar.2019.00168, indexed in Pubmed: 30930769.

15. Burt VL, Cutler JA, Higgins M, et al. Trends in the prevalence, awareness, treatment, and control of hypertension in the adult US population. Data from the health examination surveys, 1960 to 1991. Hypertension. 1995; 26(1): 60-69, doi: 10.1161/01. hyp.26.1.60, indexed in Pubmed: 7607734.

16. Ostrówka D, Jancewicz M, Komand A, et al. Awareness of the role of cardiovascular risk factors and their prevention from the perspective of Tricity adolescents. Arterial Hypertension. 2017; 21(1): 51-59, doi: 10.5603/ah.2017.0007.

17. Li C, Lumey LH. Impact of disease screening on awareness and management of hypertension and diabetes between 2011 and 2015: results from the China health and retirement longitudinal study. BMC Public Health. 2019; 19(1): 421, doi: 10.1186/ s12889-019-6753-x, indexed in Pubmed: 31014288.

18. Dymek J, Skowron A, Polak W, et al. Assessment of knowledge and skills of patients with hypertension related to self-measurement of blood pressure (SBPM). Arterial Hypertension. 2015; 19(1): 39-44, doi: 10.5603/ah.2015.0007.

19. Almas A, Godil SS, Lalani S, et al. Good knowledge about hypertension is linked to better control of hypertension; a multicentre cross sectional study in Karachi, Pakistan. BMC Res Notes. 2012; 5: 579, doi: 10.1186/1756-0500-5-579, indexed in Pubmed: 23095492.

20. Hu Y, Wang Z, Wang Y, et al. Prevalence, Awareness, Treatment, and Control of Hypertension among Kazakhs with high Salt Intake in Xinjiang, China: A Community-based Cross-sectional Study. Sci Rep. 2017; 7: 45547, doi: 10.1038/srep45547, indexed in Pubmed: 28358015.

21. Balazovjech I, Hnilica P. Compliance with antihypertensive treatment in consultation rooms for hypertensive patients. J Hum Hypertens. 1993; 7(6): 581-583, indexed in Pubmed: 8114053.

22. Knight EL, Bohn RL, Wang PS, et al. Predictors of uncontrolled hypertension in ambulatory patients. Hypertension. 2001; 38(4): 809-814, doi: 10.1161/hy0901.091681, indexed in Pubmed: 11641291. 
23. Verulava T, Nemsadze D, Jorbenadze R, et al. Factors that influence tobacco use in Georgian youth. Malta Med J. 2020; 32(2): 49-58.

24. Mukeria M, Kiknadze B, Verulava T, et al. The impact of the tobacco control law on youth tobacco use. Arch Balk Med Uni. 2020; 55(1): 108-112, doi: 10.31688/abmu.2020.55.1.12.

25. Jin J, Sklar GE, Min Sen Oh V, et al. Factors affecting therapeutic compliance: A review from the patient's perspective. Ther Clin Risk Manag. 2008; 4(1): 269-286, doi: 10.2147/tcrm.s1458, indexed in Pubmed: 18728716.

26. Sabaté E. Adherence to long-term therapies: evidence for action. World Health Organization, Geneva 2003.

27. Rubin RR. Adherence to pharmacologic therapy in patients with type 2 diabetes mellitus. Am J Med. 2005; 118 Suppl 5A:
27S-34S, doi: 10.1016/j.amjmed.2005.04.012, indexed in Pubmed: 15850551.

28. Farley TA, Dalal MA, Mostashari F, et al. Deaths preventable in the U.S. by improvements in use of clinical preventive services. Am J Prev Med. 2010; 38(6): 600-609, doi: 10.1016/j. amepre.2010.02.016, indexed in Pubmed: 20494236.

29. Peacock E, Krousel-Wood M. Adherence to Antihypertensive Therapy. Med Clin North Am. 2017; 101(1): 229-245, doi: 10.1016/j. mcna.2016.08.005, indexed in Pubmed: 27884232.

30. Kripalani S, Yao X, Haynes RB. Interventions to enhance medication adherence in chronic medical conditions: a systematic review. Arch Intern Med. 2007; 167(6): 540-550, doi: 10.1001/ archinte.167.6.540, indexed in Pubmed: 17389285. 